\title{
Terra-Mãe (1998): uma estória feita de História(s). Pistas de leitura sobre o papel social da telenovela
}

\section{Catarina Duff Burnay}

Faculdade de Ciências Humanas

Universidade Católica Portuguesa

- cburnay@fch.lisboa.ucp.pt

DOI https://doi.org/10.34913/

journals/lingua-lugar.2020.e210 
Entendido como um formato culturalmente pouco enriquecedor, a telenovela, narrativa de longa serialização com maior expressão na televisão portuguesa, dada a sua natureza complexa e de proximidade com os telespetadores, mostra-se capaz de agendar temas e de funcionar, simultaneamente, como arquivo dos tempos e relato do quotidiano. Partindo desta assunção, procuramos evidência empírica na telenovela Terra Mãe (RTP1), título produzido e transmitida em 1998, ano da Exposição Internacional de Lisboa, tendo em vista o desejo de desenhar pistas de leitura sobre o papel social da televisão e dos conteúdos ficcionais.

Palavras-chave: Ficção televisiva; telenovela; identidade; representação.

Perçu comme un format culturellement peu enrichissant, le feuilleton est une série de longue durée qui trouve amplement sa place à la télévision portugaise, étant donné sa nature complexe et sa proximité avec les téléspectateurs. Ce genre de récit se révèle capable de programmer des thèmes, et de fonctionner simultanément comme une archive de l'époque et comme un récit de la vie quotidienne. Partant de cette hypothèse, nous recherchons des preuves empiriques dans Terra Mãe (RTP1), série produite et diffusée en 1998 (année de l'Exposition Internationale de Lisbonne), en essayant de relever des indices de lecture sur le rôle social des contenus fictifs et de la télévision dans la société.

Mots-clefs: Fiction télévisuelle ; feuilleton ; identité ; représentation 
Formato-âncora dos canais generalistas portugueses em sinal aberto desde 1977, nomeadamente nos canais comerciais SIC e TVI nos últimos 20 anos, a telenovela tem tido a capacidade de estabelecer uma ligação próxima e continuada com o público. A sua natureza lúdico-afetiva (Fuenzalida, 1994) eleva a telenovela a um lugar de destaque nas grelhas de programação (horário nobre), contribuindo para o desempenho audimétrico positivo das estações e, em consequência, para a permanência do investimento publicitário, sustentáculo dos canais privados. Esta ideia, por si só, remete, de imediato, para as ideias pré-concebidas sobre a estrutura fechada e formulaica do formato, assim como sobre o seu efeito brainwash nos indivíduos, na linha de pensamento frankfurtiana sobre a qualidade e o impacto dos produtos da cultura popular na sociedade (Adorno, 1985; Condry e Popper, 1995; Mander, 1999). Esta realidade acaba por ter ecos na esfera académica, predominando uma abordagem apocalíptica sobre os conteúdos ficcionais como objetos de estudo, numa lógica de hierarquia cultural (Buonanno, 1999; Motter, 2000; Borelli, 2001; Burnay, 2005).

Herdeira dos contos de Sherazade, do folhetim do século XIX, da rádio e fotonovela, num claro processo de "remedição" (Bolter e Grusin, 1999), a telenovela foi ganhando dimensão no espaço ibero-americano enquanto formato televisivo autónomo, distinto da soap opera de tradição anglo-saxónica - o mais similar - e de outros formatos ficcionais. Para além disso, embora partilhe as componentes áudio e vídeo com o cinema, foi construindo uma estrutura diferenciada, partilhando alguns dos elementos, mas não se encaixando, de forma exata, nas propostas teóricas usadas e/ou nascidas na/com a sétima arte, como as de Propp (2003), Field (2003), Campbell (1968) ou Vogler (2007).

Nascida em 1982 (Vila Faia, RTP), a telenovela portuguesa - que esteve quase para se chamar teleromance - embora tenha nascido moldada com base nos títulos brasileiros transmitidos pela RTP desde 1977, foi trilhando um caminho próprio, sofrendo mutações numa adaptação aos tempos dos media, da televisão, da programação e da receção, assim como aos tempos da própria sociedade, revestindo-se de especificidades. A prática de legendagem de conteúdos estrangeiros, por exemplo, fez com que o horário nobre dos canais em sinal aberto (20:00-24:00) apenas pudesse oferecer conteúdos nacionais ou falados em português (Brasil). Neste sentido, sendo um slot em que existem mais indivíduos disponíveis para consumir televisão e com características muito diferenciadas, as telenovelas surgiram como conteúdo interessante para preenchê-lo, permitindo, numa aproximação aos quotidianos e à contemporaneidade, 
acompanhar as rotinas dos telespetadores, independentemente da idade, género ou classe social. É, precisamente, neste sentido, que se entende a telenovela como um folhetim moderno e destinado a um público familiar, albergando em si uma pluralidade de géneros. Para além disso, as histórias ficcionadas de longa duração oferecidas hoje pela televisão nacional são narrativas complexas, têm uma pluralidade de núcleos, um número elevado de personagens com características sociodemográficas heterogéneas, exploram tramas paralelas e confluentes de base real e oscilam entre a linearidade, múltiplos momentos catárticos e cliffhangers. Contrariamente ao expectável, estes textos exigem leitores competentes e fiéis, capazes de evoluir de audiência a público (Abrantes e Dayan, 2006).

\section{O papel social da Telenovela}

Os conteúdos de ficção, em especial a telenovela pela sua dimensão contemporânea, permitem, de forma recorrente, agendar temas em/ para debate em espaço público (Lopes, 2009). Seguir tendências e oferecer várias perspetivas sobre o mesmo fenómeno consubstancia o formato como mais um meio de informação e esclarecimento capaz de complementar os restantes meios de informação disponíveis. Este paralelo com o campo informativo pode, inclusivamente, ser aprofundado, se imaginarmos as funções/teorias jornalísticas como o agenda-setting ou o newsmaking aplicadas às telenovelas (Cunha, 2011), não obstante o debate teórico e científico polarizado sobre estas teorias ${ }^{1}$ e de uma

$\mathbf{1}_{\text {Ver, entre outros, Sousa, } 2000 .}$ potencial controvérsia sobre a sua aplicabilidade à ficção. O que podemos observar é que, para além dos temas tradicionais que compõem uma narrativa desta natureza (triângulo amoroso, vingança, revelação/ocultação de identidade), é exercida uma constância dialógica entre o real e a ficção, permitindo a exposição de temas sociais e/ou em debate na sociedade. São vários os estudos que mostram que, para lá da apresentação de histórias que mimetizam o dia a dia, os textos têm a capacidade intrínseca de veicular, de forma simultânea, informações de interesse público de efeitos imediatos (por exemplo, incentivo ao rastreio de doenças, à reciclagem) e informações de interesse público de efeitos a médio e longo prazo, logo, cognitivos (por exemplo, apresentação de temas fraturantes em discussão no espaço público ou histórias do passado coletivo) (Bosi, 1992; Lopes, 2009, 2003; Machado, 2007). Esta realidade remete para práticas que cruzam diversas áreas científicas, mas que encontram apoio nos media, nomeadamente na ficção, como a Education Entertainment (Singhal et al., 2004) ou o Merchandising Social (Schiavo, 2002). 
Neste âmbito, Maria Immacollata Lopes (2009), invocando Homi Bhabha (2006), vai mais longe e propõe olhar a telenovela como uma "narrativa popular sobre a nação" - embora acautele a dimensão performativa de uma ideia de nação - atendendo à sua capacidade de trabalhar com os princípios identitários dos brasileiros, promovendo o interesse local, mas também permitindo suscitar o interesse global dentro da dinâmica "identificação-fascinação". Partindo desta assunção, não entendemos a telenovela portuguesa como veículo edificador de uma potencial coesão nacional, mas como um "arquivo dos tempos" (Lopes, 2014), plástico e adaptável, um meio privilegiado, dada a sua natureza e evolução, para, quando necessário, servir causas comuns. A sua real eficácia fica, contudo, condicionada pelo momento de codificação (construção da mensagem) e, por consequência, pela descodificação e leituras realizadas pelos diferentes grupos sociais (Hall, 1973).

\section{8: o ano da Expo (e não só)}

A década de 90 do século XX em Portugal foi particularmente rica em termos culturais. A sensação de "isolamento" foi ultrapassada com grandes marcos, como a presença de Portugal na Europália-Festival Cultural em Bruxelas em 1991, Lisboa-Capital Europeia da Cultura em 1994, a escolha do país e da sua literatura como tema central da Feira do Livro de Frankfurt em 1997 ou a atribuição do Prémio Nobel da Literatura a José Saramago em 1998. O motto Caminhos no Mundo da Feira do Livro de Frankfurt abriu "caminho" à Exposição Internacional de Lisboa. Ideia tida em 1989 por António Mega Ferreira e Vasco Graça Moura, responsáveis pela Comissão Nacional para as Comemorações dos Descobrimentos Portugueses, viu a luz do dia em 1998, quando a 22 de maio se abriram as portas da Expo'98 (como ficou conhecida

2 Criada pelo Decreto-Lei n. ${ }^{0} 177 / 96$, de 21 de setembro, com capitais do Estado, da Sociedade Anónima Parque Expo'98, SA e da Associação Portuguesa de Editores e Livreiros, a sociedade anónima Portugal-Frankfurt 97, tinha como objetivo a promoção da presença de Portugal como país-tema na 49. ${ }^{a}$ Feira do Livro de Frankfurt. a Exposição) sob o lema Os Oceanos, um património para o futuro. À evocação dos Descobrimentos, numa espécie de exaltação/nostalgia de um passado comum e de (re)construção da memória coletiva (Halbwachs, 1992) foi concomitante o entendimento dos mares como património comum da Humanidade e como estímulo à cooperação regional, económica, científica e política. Na verdade, e como descrito no Relatório da Exposição Mundial de Lisboa de 98, pretendia-se "propor uma nova ética nas relações do homem com o meio ambiente, tema que (...) parecia central na agenda política do século XXI" (Relatório, 1999, p. 18). 
A zona oriental da cidade de Lisboa, abandonada, ganhou uma nova vida fruto de um processo ativo de reabilitação, a par da construção de edifícios de arquitetura contemporânea e futurista que ajudaram a transmitir uma ideia simbólica de monumentalidade do país, preparado para entrar no século que dealbava.

Aos edifícios carregados de simbolismo imperial e que eram valorizados enquanto testemunhos de uma identidade irredutivelmente portuguesa - os Jerónimos, a Torre de Belém - sucederam, no recinto da Expo 98, os associados a uma nova narrativa: a da modernidade e capacidade dos portugueses para realizarem o mesmo que os outros, demonstrando assim a capacidade para se integrarem no seu seio (Sobral, 1999, p. 72).

Ainda em 1998, e dentro do espírito celebratório do passado para projetar o futuro, foi inaugurada a maior ponte da Europa Ocidental, chamada Ponte Vasco da Gama e o Centro Comercial Colombo, as maiores galerias comerciais da Península Ibérica. No ano seguinte, no espaço físico da Expo'98, nasceu o Centro Comercial Vasco da Gama.

Nos campos político e social, parece-nos interessante ressaltar a realização dos primeiros referendos no país (regionalização e despenalização do aborto), enquanto instrumentos democráticos e de participação e, no plano mediático, para além da produção e transmissão da telenovela Terra Mãe pela RTP, que desenvolveremos a seguir, consideramos curiosa a produção da primeira longa-metragem falada inteiramente em inglês Sweet Nightmare. Assinada por Fernando Fragata, coproduzida pela SIC e apoiada pelo Instituto do Cinema, do Audiovisual e Multimédia (ICAM), o filme contou com atores conhecidos e popularizados pela televisão (Catarina Furtado e Diogo Infante). Apesar de algumas críticas menos positivas (Ramos, 2006) e de não ter sido um sucesso de bilheteira, a longa-metragem teve o mérito de procurar ser diferente, mais comercial e de ultrapassar fronteiras, situando-se, pelo menos no plano das intenções, mais próxima das tendências (pós) modernas de então.

\section{Terra Mãe: uma estória feita de História(s)}

Terra Mãe é a metáfora de uma cidade que mandou os seus filhos em aventura pelo mundo e agora recebe os 'netos' em sua casa. Esta metáfora é simbolizada pela atriz que acolhe e protege em sua casa três imigrantes de expressão portuguesa, um dos quais carrega consigo um grande segredo. O relacionamento destas quatro personagens representa a cooperação de Portugal com os outros povos que falam português. Esta telenovela conta a história de Milú Mendes, 
uma divertida atriz de Teatro reformada, que arrenda quartos em sua casa, iniciativa que não é vista com bons olhos pela sua neta, a Carla. Neste espaço vão conviver três jovens de diferentes nacionalidades: Hugo, um jornalista Moçambicano desiludido com a falta de perspetivas no seu país, Kim, vem de Macau preocupada com a incerteza económica e política da sua terra após a retomada chinesa, estuda estilismo em Portugal, e por fim, Felipe, um brasileiro licenciado em comunicação, filho de imigrantes portugueses que traz um enorme segredo consigo na mala. Ao chegar a Lisboa e em circunstâncias aparatosas, Felipe conhece Ana, uma jovem simpática e de boas famílias, e os dois sentem uma forte atração. Porém, as possibilidades de iniciarem uma relação estão comprometidas, pois Ana mantém um namoro de anos e casamento iminente com Henrique e terá ainda de enfrentar os preconceitos da sua avó, Maria do Carmo, mulher conservadora, preconceituosa e capaz de tudo para defender os interesses familiares e do irmão mais novo, Gonçalo, que nunca viu com bons olhos a presença de estrangeiros em Portugal. Maria do Carmo é irmã de Milú, sendo que as duas mantêm desde sempre uma relação tensa e distante. Também Diogo, neto mais velho de Maria do Carmo, viu mal terminado o seu caso amoroso de adolescente com Carla, como consequência das pressões da avó, que nunca aceitou a relação dos dois. Em Lisboa, Felipe reencontra também a sua amiga e ex-namorada, Fernanda, uma brasileira que partilha um pequeno apartamento com dois amigos, Luís e Marcelo. O grupo de jovens boémios convive ainda com Patrícia, rapariga deslumbrada que não desiste de casar com um homem rico que lhe garanta um bom nível de vida. Isabel vive há anos um casamento de fachada com Zé Maria. A família gere uma cadeia de boutiques, as lojas Vincenzo, propriedade do pai de Isabel, Augusto. O que ela não sabe é que o seu marido mantém uma outra família em segredo, constituída por Fátima e Helena, que desconhece que o pai é, na verdade, aquele a quem sempre tratou por padrinho. Em paralelo, assistimos a uma história policial que envolve a perseguição levada a cabo pelos mafiosos Álvaro e Tito a um chip informático e à chave "Laika", que se encontra na posse de Felipe. No culminar da intriga, tem-se ainda o assassinato de Marina, publicitária na agência Zenith. $^{3}$

Produzida e transmitida pela/na RTP1, entre 9 de março e 4 de setembro de 1998, a história da autoria de Rui Vilhena tem como temas base "a imigração, os dramas familiares e os romances proibidos". 4 No site do Arquivo da estação de serviço público, a telenovela é ainda descrita como uma "comédia de costumes de caráter policial passada no ambiente multicultural da modernização de Lisboa durante a Expo'98". 5 Para além de apresentar o conteúdo, este descritivo alude às duas dimensões-chave usadas na construção/

3 A presente sinopse é uma adaptação da sinopse mais completa encontrada online. Não obstante a pouca fiabilidade da fonte (Wikipedia), apresenta a trama e as personagens e enredos de forma clara: Terra Mãe, Wikipedia, https://pt.wikipedia. org/wiki/Terra_M\%C3\%A3e acedido a 4 de janeiro de 2020.

4 4 Informação institucional disponível no site da RTP: https://www.rtp.pt/programa/ tv/p8675

5. mação institucional disponível no site do Arquivo da RTP: https://arquivos. rtp.pt/conteudos/terra-mae-episodio-01/ 
desconstrução do texto - o "ambiente multicultural" e a "modernização de Lisboa [durante a Expo'98]" - permitindo-nos construir o seguinte

modelo de análise.

A Dimensão 1 - Ambiente Multicultural - foi explorada através das dinâmicas intra e interpessoais, inter e intragrupais de três personagens jovens de origem brasileira (Felipe), moçambicana (Hugo) e macaense (Kim) com a Lisboa, o Portugal, os Lisboetas e os Portugueses da trama. A Dimensão 2 - Modernização de Lisboa - foi trabalhada pela apropriação de landscapes naturais da cidade de Lisboa e de práticas sociais da época. Para compreender como se materializam estas duas dimensões de análise na narrativa, procedemos à criação de dois conjuntos de indicadores - indicadores contextuais (elementos materiais e estéticos dos espaços e personagens) e indicadores textuais (elementos textuais/ discursivos e não verbais dos espaços e personagens).

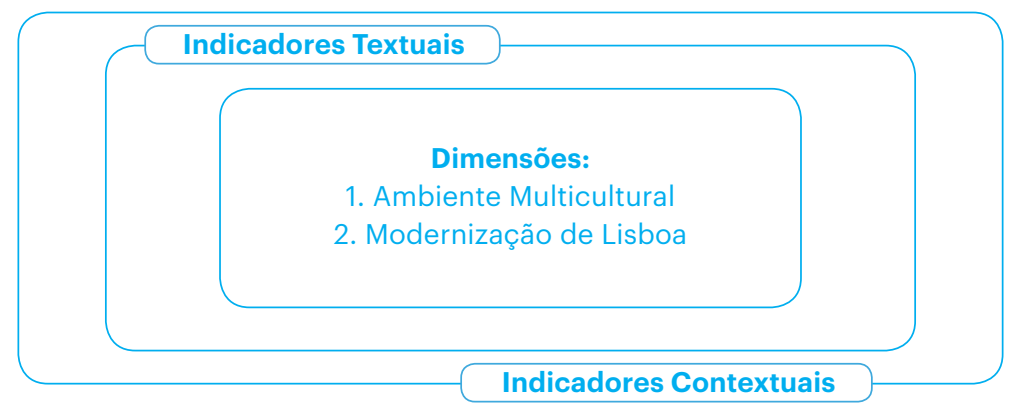

No momento seguinte, procedemos ao visionamento da totalidade dos capítulos (146), disponíveis no Arquivo Digital da RTP, ${ }^{6}$ perfazendo 103 horas (42,35 minutos/capítulo de duração média). Tendo por base o modelo de análise, no decurso do vision-

6 Agradecemos ao Arquivo Digital RTP na pessoa do Dr. Lopes de Araújo, pela disponibilização do conteúdo. amento da telenovela, fomos mapeando momentos e elementos que se mostraram pertinentes para a compreensão da forma como as dimensões e os indicadores identificados dialogavam.

\section{Dimensão 1 - Ambiente Multicultural}

Composto pelas palavras "Terra" e "Mãe", o título da telenovela alude, por um lado, à expressão "Língua Mãe" (neste caso a língua portuguesa) e a um território geográfico comum numa invocação do "império português". Em segundo plano, desenhada a dourado, a rosa dos ventos faz o contraponto com os oceanos e com o período dos Descobrimentos. Esta imagem é precedida por uma sequência de outras imagens, apresentadas 
de forma aleatória e repetida, de quatro mulheres representativas dos territórios africano, chinês, brasileiro e português, quer em traços físicos, quer pelas vestes envergadas. A rosa dos ventos vai passando de frame para frame, sendo substituída por um astrolábio e por uma caravela. As mulheres representam as nacionalidades das personagens centrais - Hugo (moçambicano), Kim (macaense) e Felipe (brasileiro) - os três recém-chegados a Portugal em busca de uma vida melhor (por exemplo, Hugo: "saí de Moçambique com o objetivo de atingir os meus objetivos em terra Lusa"; Kim: "é difícil arranjar emprego na minha área e não sei o que vai acontecer quando o território passar a ser chinês").

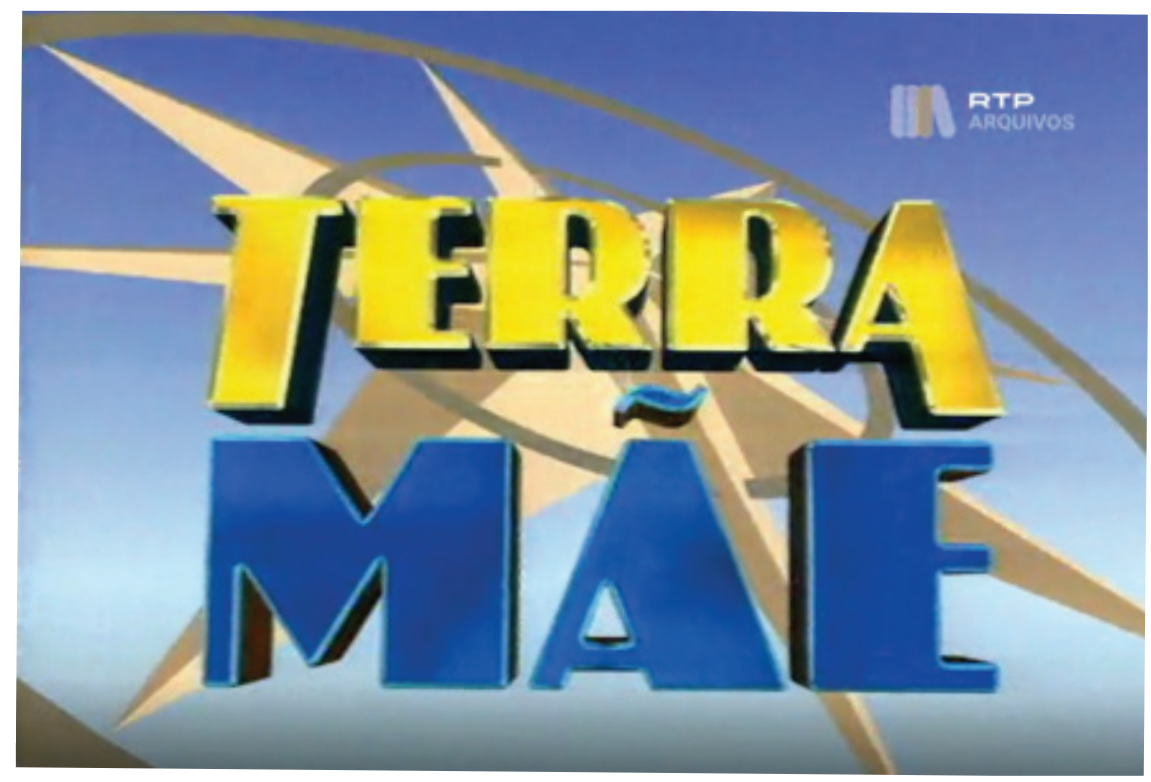

\section{imagem 1}

Logótipo da telenovela apresentado no genérico. Fonte: Arquivo RTP

D. ${ }^{a}$ Milú, a personagem mais velha e de nacionalidade portuguesa que recebe os jovens em sua casa, promove o encontro de culturas e o esbatimento entre diferenças culturais (por exemplo, Hugo: "Nasci em Maputo" / D. ${ }^{a}$ Milú: "Na altura, Lourenço Marques... mas os nomes não interessam nada"). Estas ideias são reforçadas com a relação amorosa principal da narrativa entre o brasileiro Felipe e a portuguesa Ana. Com um percurso muito atribulado, a união dos dois, selada com um beijo, fecha o capítulo 146 da telenovela, numa clara demonstração de harmonia e convivialidade das personagens e, por consequência e de forma imaginada, dos povos de expressão portuguesa.

A representação pacificada da relação entre povos diferentes é pontuada pelo recurso ao reforço de estereótipos, nomeadamente sobre a "delicadeza 
oriental" de Kim, o "misticismo brasileiro" de Felipe, a vontade do rececionista da pensão em ir ao Brasil ver "praias e garotas" ou a ideia de que os orientais são todos iguais. Os media, nomeadamente a televisão, dada a sua natureza audiovisual e o seu alcance, são veículos privilegiados para trabalhar as representações. Contudo, o objetivo de chegar de forma imediata leva, muitas vezes, a simplificações e a condensações (Cunha e Santos, 2004), contribuindo para interpretações parciais ou, no limite, distorcidas. É neste ponto que introduzimos Gonçalo, irmão de Ana, a única personagem que, de forma transparente, se opõe à presença de estrangeiros em Portugal. Para além de um comportamento desconcertante, tendo em vista um percurso de vida facilitado, Gonçalo confronta diretamente Felipe sobre a permanência em Lisboa e na empresa do pai, destacando-se o diálogo no capítulo 81, não só pelo seu conteúdo, mas também pelo tom usado pelas duas personagens (Gonçalo: "és um imigrante. Volta para a tua terra" / Felipe: "já voltei... para a minha terra lusa"). Se, por um lado, Gonçalo usa um tom acusatório e inflamado, Felipe mede cada palavra numa posição de segurança e certeza de também pertencer a Portugal.

Uma análise aos três posicionamentos identificados nesta primeira dimensão - 1) abertura ao "desconhecido"; 2) invocação de estereótipos sobre o "desconhecido"; 3) fechamento ao "desconhecido" - mostra uma presença desequilibrada na história, predominando, em termos de referência/importância, a construção de um uníssono de vozes em apelo ao consenso. Este facto, parece favorecer a construção de uma narrativa branda, ignorando, por exemplo, o passado histórico de relações, como o período dos descobrimentos e as suas consequências para os povos das ex-colónias. A este propósito, Marta Araújo (Araújo e Rodrigues, 2018; Araújo e Maeso, 2013) tem explorado a forma como os manuais escolares da disciplina de História têm contribuído para a construção de uma narrativa despolitizada sobre a escravatura e de uma naturalização do colonialismo, numa dinâmica constante de (in)visibilidades.

Esta ideia é reforçada na última imagem da telenovela, quando, após muitas peripécias, os três jovens preparam uma refeição para surpreender a D. a Milú, em forma de agradecimento por os ter recebido em sua casa. A postura corporal dos jovens, abraçados e ligeiramente curvados, contrasta com a entrada triunfante da senhoria na cozinha ("a alma da casa" nas palavras da D. ${ }^{a}$ Milú), numa potencial alegoria dos feitos e conquistas dos portugueses além-mar e das boas relações multiculturais em torna da língua portuguesa, consubstanciados em conceitos (polémicos) como Lusofonia ou Luso-Tropicalismo. ${ }^{7}$

7 Ver, entre outros, Sousa, 2017. 


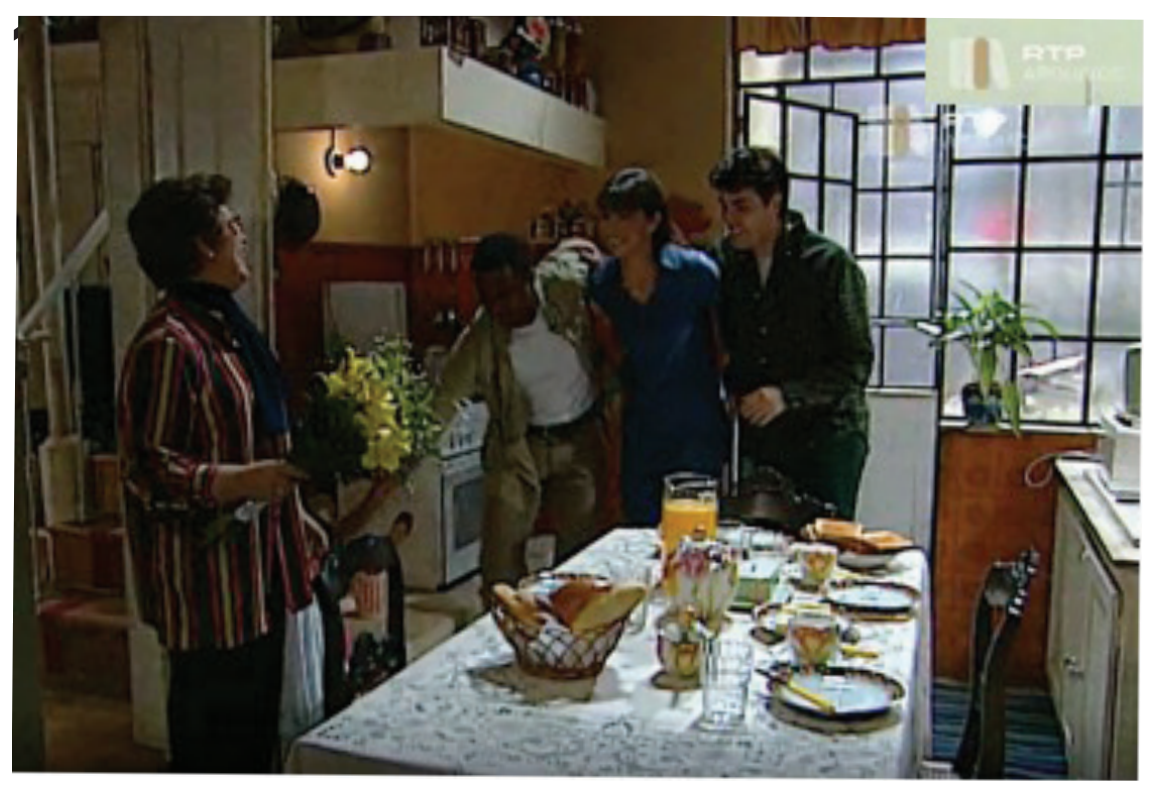

\section{imagem 2}

Última cena da telenovela,

Fonte: Arquivo RTP

Na senda desta ideia, é de notar as inúmeras referências - imagéticas e verbais - à importância de Portugal na descoberta do mundo e na promoção da relação entre os povos, proposta edificadora do projeto Expo'98. No seu Guia Oficial, é possível reconhecer, na voz dos governantes do Portugal de então, esses desígnios:

“Hoje, com a Expo'98, retomamos o processo de comunhão entre diferentes povos e civilizações" (António Guterres, Primeiro Ministro);

"A história colocou em lugar de destaque os méritos dos Portugueses no alargamento do universo conhecido e na promoção de um dos mais significativos processos de partilha de culturas"

(António Costa, Ministro dos Assuntos Parlamentares);

“É uma grande honra para Portugal acolher e organizar a última exposição mundial do século e do milénio, neste ano de 1998, em que também se comemora a chegada dos Portugueses à Índia, numa viagem marítima que mudou a economia mundial, a geografia dos encontros de culturas e a comunicação entre os povos" (Jorge Sampaio, Presidente da República). (Guia Oficial da Expo'98, 1998, pp. 8, 10, 12, itálicos da autora)

Em Terra Mãe, esta ideia, para além de ser corporizada pela essência e ação das personagens principais, faz-se pela representação de símbolos nacionais, como, por exemplo, os aviões da companhia de bandeira, TAP Air Portugal, numa clara invocação de ideias como a "viagem", "ponte entre os povos", "tolerância e solidariedade", mas também, e de forma velada, "supremacia". 
Em adição, é de referir a inserção de cenas desenroladas dentro do aeroporto da Portela (Lisboa), dando continuidade à ideia de "viagem" e à chegada a um país de "braços abertos", mas diferente: moderno, cosmopolita e visionário (Metrópole). Neste sentido, ressalta-se a apresentação, por diversas vezes, da arquitetura do espaço, numa reminiscência estética da Estação do Oriente (Santiago Calatrava), equipamento inaugurado em 1998 no âmbito da exposição mundial e que, ainda hoje, tem um lugar de destaque na oferta cultural da cidade.

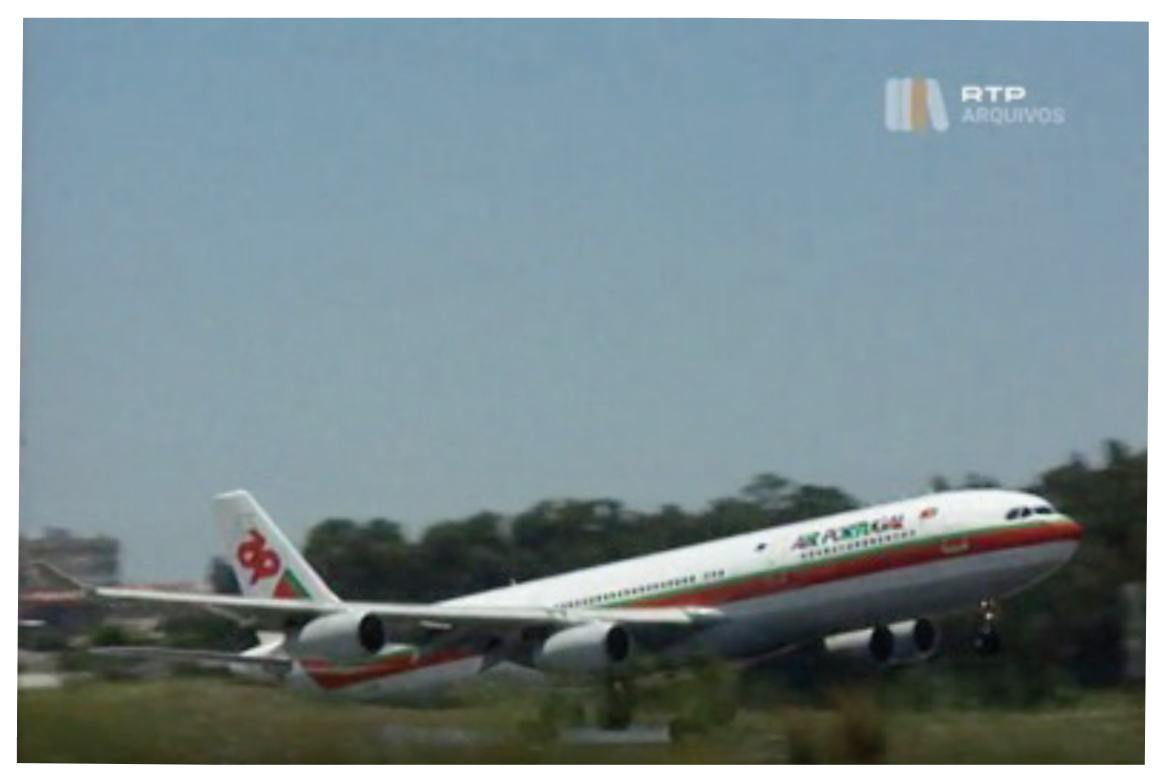

imagem 3
Avião da TAP Air Portugal,

Fonte: Arquivo RTP

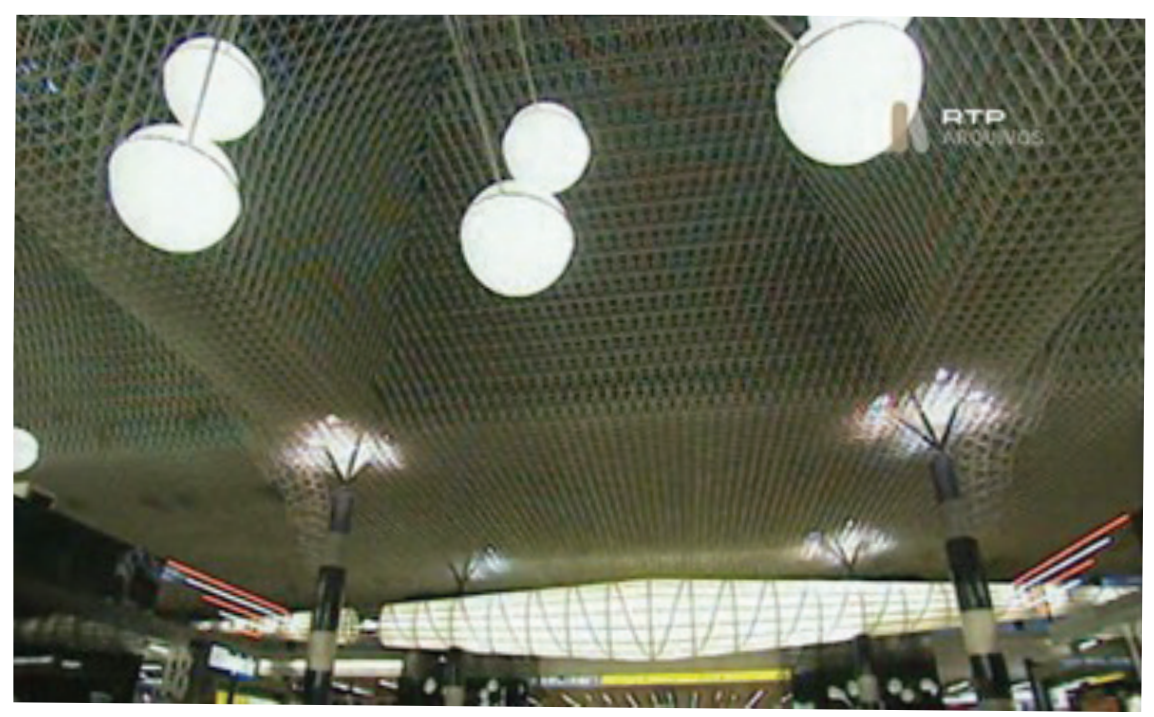

\section{imagem 4}

Aeroporto da Portela (Lisboa),

Fonte: Arquivo RTP 
A exposição em si também tem um papel de destaque na telenovela, ora como set de algumas cenas, ora como separador entre cenas. De forma recorrente, surge no ecrã um mash-up de imagens panorâmicas e de pormenor dos espaços exteriores do recinto e envolventes, de transeuntes reais e das personagens, acompanhada de uma música "eletrizante", o que oferece uma sensação de dinamismo, própria de uma grande cidade europeia. Esta oferta cultural é pontuada por imagens do Centro Comercial Amoreiras, o primeiro shopping surgido em Portugal (1985) e o recém-inaugurado Centro Comercial Colombo (1997), o maior shopping da Península Ibérica. Se o primeiro provocou uma acesa polémica na década de 1980, fruto da sua arquitetura disruptiva, o segundo foi esperado com ansiedade e assumido como mais um passo para responder às necessidades da economia de mercado. Um dos espaços importantes na trama é a loja Vicenzo, marca de alta costura pertencente a uma das famílias. Situada no Centro Comercial Colombo, é frequentada pelos membros da alta sociedade, explorando-se, de maneira recorrente, as comparações com a classe e qualidade das vitrinas e dos modelos, numa alusão ao oferecido nas reconhecidas cidades de Londres e Nova lorque.

A aposta nas cidades como motores da economia, embora já integrasse as estratégias de muitos países, ganhou dimensão exatamente em 1997 quando Tony Blair venceu as eleições no Reino Unido e estabeleceu como uma das metas da sua legislatura a aposta no mapeamento e organização das indústrias criativas. Conceito herdeiro da "indústria cultural" da Escola de Frankfurt, ${ }^{\mathbf{8}} \mathbf{8}$ Ver Adorno e Horkheimer [1947] 1985. não existe, até hoje, uma definição amplamente aceite, havendo sim, e no entanto, algumas orientações base que devem ser atendidas, tais como o uso e desenvolvimento dos produtos e produtores culturais para a criação e circulação de capital cultural, para a geração de emprego, a promoção da inclusão social, da diversidade cultural e do desenvolvimento humano (Creative Economy Report 2008, 2008).

Outra linha de representação de uma ideia de modernidade é a presença variada e persistente de "tecnologia". Aqui entendida em uma aceção lata, são várias as imagens que mostram o uso da internet, de computadores, de telefones portáteis e telemóveis, numa tentativa de normalização do seu uso e de capitalização das suas vantagens dentro de um estilo de vida cosmopolita e moderno. 


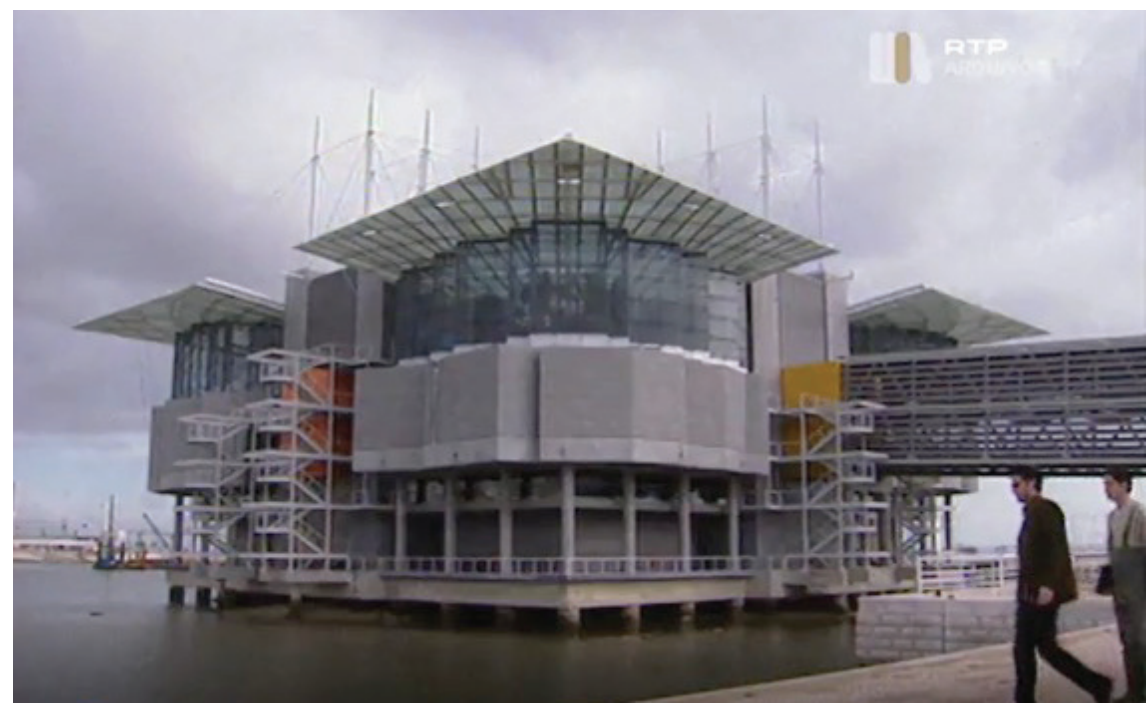

\section{imagem 5}

Oceanário de Lisboa,

Fonte: Arquivo RTP

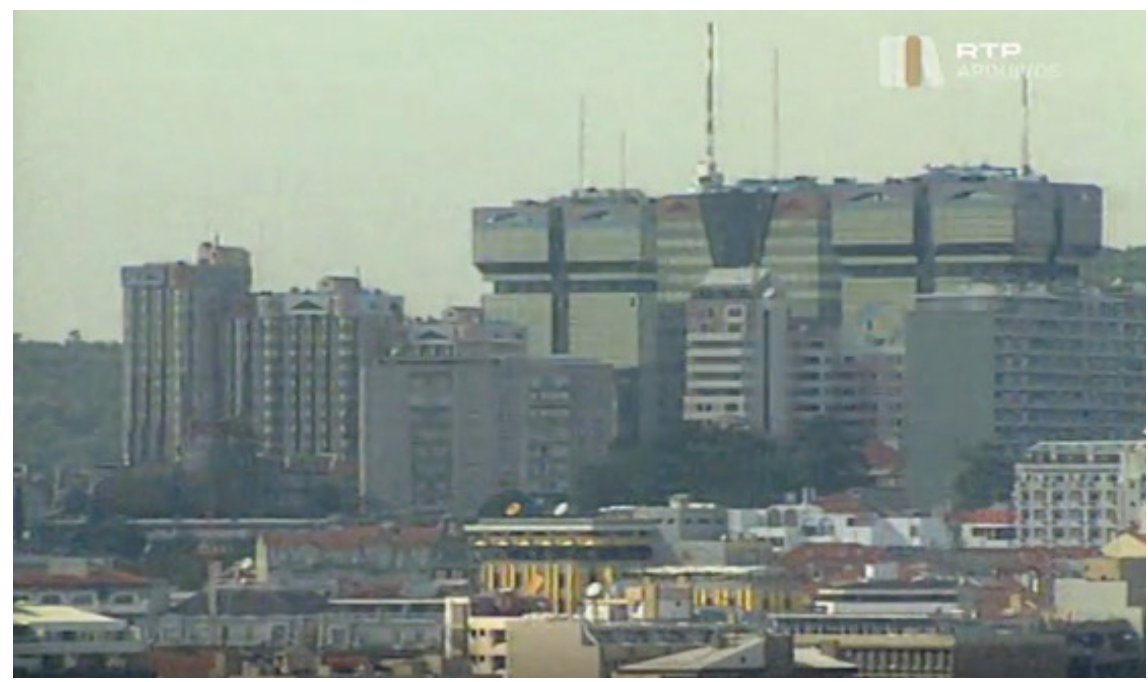

\section{imagem 6}

Centro Comercial das Amoreiras,

Fonte: Arquivo RTP

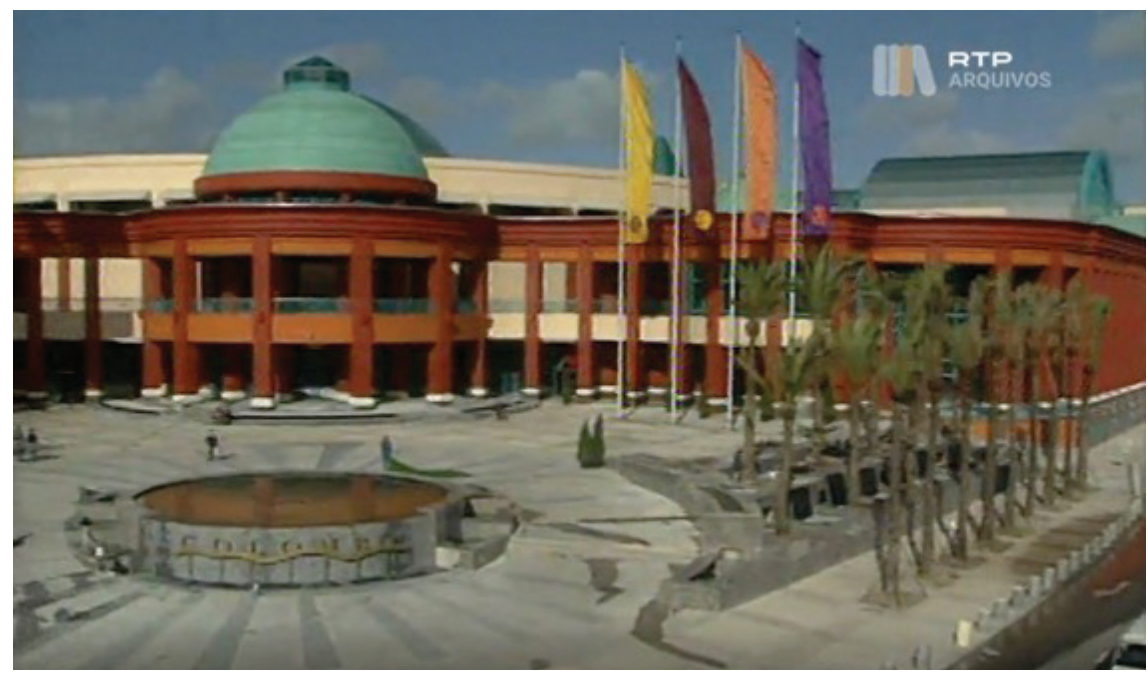

imagem 7

Centro Comercial do Colombo,

Fonte: Arquivo RTP 


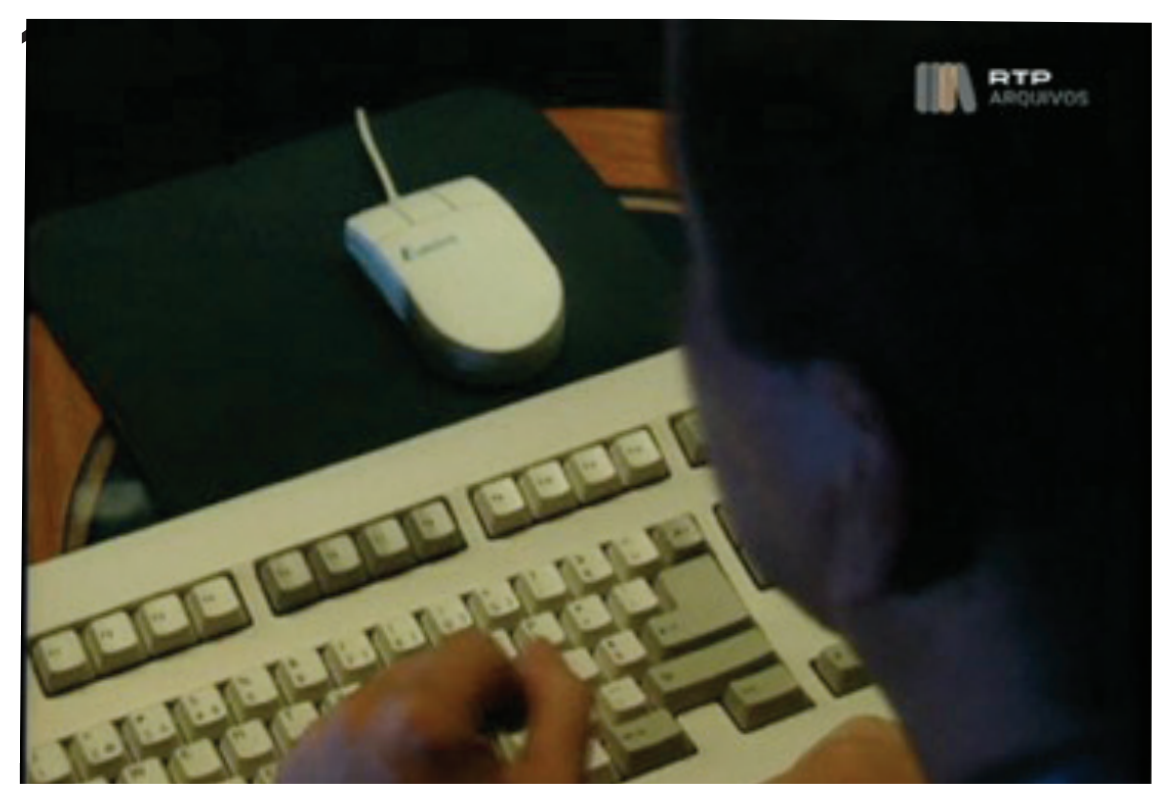

\section{imagem 8 \\ Computador}

Fonte: Arquivo RTP

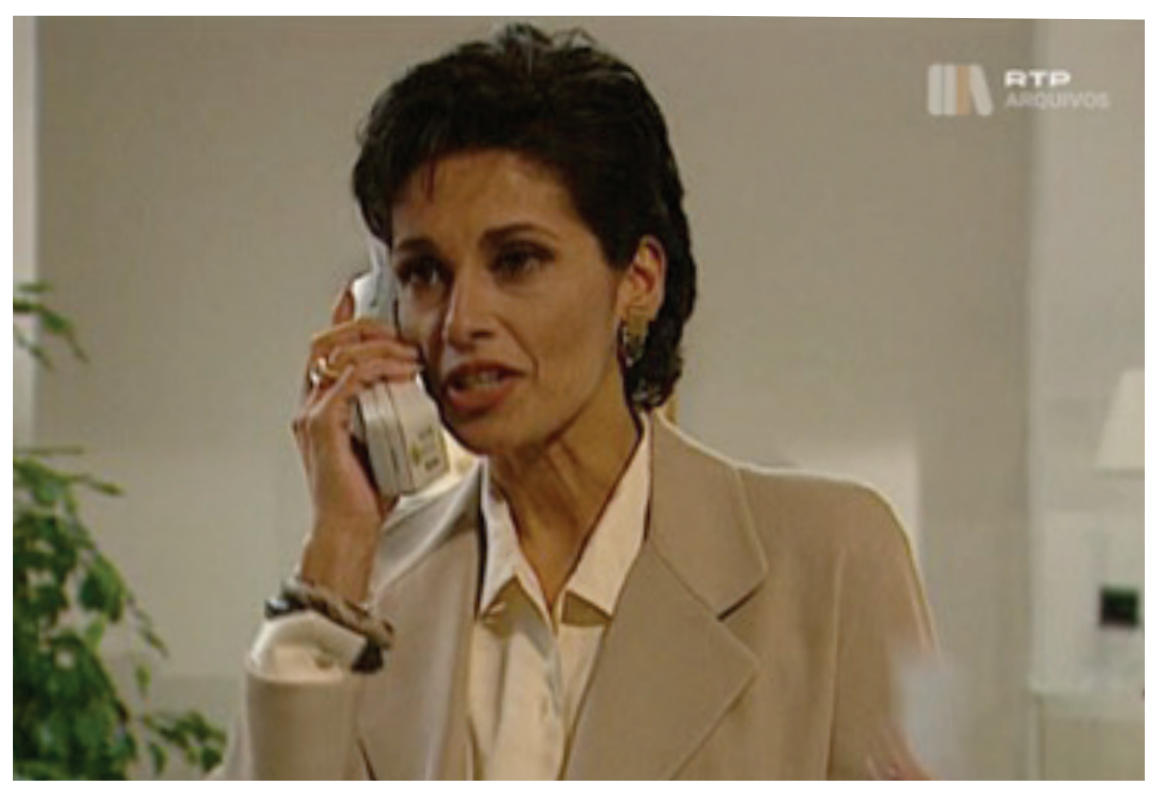

\section{imagem 9 \\ Telefone portátil, \\ Fonte: Arquivo RTP}

\section{Considerações Finais}

As mensagens-chave veiculadas pela telenovela Terra Mãe, embora simbolicamente tipificadas e, por vezes, fechadas a um entendimento plural, procuram através de uma linha narrativa sincrónica - Passado (Descobrimentos), Presente e Futuro (Expo'98; Centros Comerciais; Cidade Criativa) - (re)produzir a imagem de uma (nova) cidade, e mesmo de país, capacitada para responder aos desafios de um novo século que se avizinhava. Em simultâneo, procura, através da narrativa central, 
desmistificar um passado (potencialmente) traumático promovendo, não um apagamento da História, mas uma espécie de reescrita da História. Por natureza, e contrastando com os primeiros estudos de comunicação sobre os efeitos dos media nos indivíduos, ${ }^{9}$ os textos são polissémicos e as leituras, em consequências, plurais. Esta ideia mostra-se interessante para entender a televisão e, mais concretamente, as telenovelas, como um produto de fluxo
9 Nos primeiros estudos, ligados ao funcionalismo americano, os efeitos dos media nos indivíduos eram considerados diretos e ilimitados (formulação das balas mágicas). capaz de fornecer informação sobre o passado aos telespectadores, mas, também, servir de montra do hoje para o futuro. Não obstante este posicionamento, claramente identificado neste exercício, Terra Mãe oferece também uma narrativa paralela de entendimento, propondo não "um retorno ao passado (...), mas antes ao presente no qual circulam as narrativas sobre o passado" (Araújo e Rodrigues, 2018, p. 109). Neste sentido, parece ter havido, deliberadamente, a intenção de construir mais uma camada de significados em cima da História, projetando um ideal de modernidade instalada, fundada na conquista dos mundos e na essência fraterna dos portugueses.

Pelo exposto, parece que encontramos um paradoxo - a telenovela tem potencial para funcionar como "lugar de memória" (Nora, 2001 [1993]) e contribuir para uma melhor compreensão dos tempos através de uma abordagem às realidades passadas e presentes, porém, o exemplo trabalhado, e potencialmente outros que o legado da ficção audiovisual tem deixado, mostram que continuam a existir abordagens distorcidas sobre certos temas quando passados a estórias, limitando as potencialidades dos meios como agentes de memória, mas enfatizando as potencialidades dos meios como construtores de memória. Embora esta realidade não apague o potencial positivo do formato ficcional, vem contribuir, em certa medida, para o perpetuar de ideias feitas sobre a qualidade e função dos conteúdos ficcionais e, no limite, sobre a televisão enquanto meio. 


\section{Bibliografia}

Abrantes, J.C., Dayan, D. (org.). (2006). Televisão. Das audiências aos públicos. Lisboa: Livros Horizonte.

Adorno, T., Horkheimer, M. [1947] (1985). Dialética do Esclarecimento. São Paulo: Jorge Zahar.

Araújo, M., Rodrigues, A. (2018). “História e memória em movimento: escravatura, educação e (anti)racismo em Portugal". Revista História Hoje, v. 7, n. ${ }^{\circ}$ 14, 107-132.

Araújo, M., Maeso, S. (2013). Caderno de discussão. 'Ao fim e ao cabo, foi a Europa que fez o mundo moderno': o Eurocentrismo na História e nos seus Manuais. Centro de Estudos Sociais, Universidade de Coimbra.

Bhabha, H. (2006). Nation and Narration. New York: Routledge.

Bolter, J., Grusin, R. (1999). Remediation. Understanding new media. Cambridge: MIT Press.

Borelli, S. H. S. (2001). Telenovelas

brasileiras: balanços e perspectivas. São Paulo em Perspectiva, São Paulo, 3, v. 15, pp. 29-36.

Bosi, A. (1992). Dialética da colonização. São Paulo: Companhia das Letras.

Buonnano, M. (1999). El drama televisivo. Identidad y contenidos sociales. Barcelona: Gedisa Editorial.

Burnay, C. D. (2005). "A Telenovela e o Público: uma relação escondida". Revista Media e Jornalismo, Lisboa: CIMJ. pp. 95-110.

Campbell, J. (1968). The Hero with thousand faces. California: New World Library.

Condry, J., Popper, K. (1995). Televisão: um perigo para a Democracia. Lisboa: Gradiva.

Cunha, I., Santos, C.A. (2004). Media, imigração e minorias étnicas - 2005-2006. Lisboa: ACIME/Observatório de Imigração.

Cunha, I. (2011). Memória da Telenovela. Programas e recepção. Lisboa: Livros Horizonte.

Field, S. (2005). Screenplay. The foundations of screenwriting. USA/Canada: Delta.

Fuenzalida, V. (1996). “La apropiación educative de la telenovela". Diálogos de la Comunicación, n. ${ }^{\circ} 44$, pp. 91-105.
Guia Oficial Expo'98. (1998). Lisboa: Parque Expo'98

Halbwach, M. (1992). On Collective Memory. Chicago: University Chicago Press.

Hall, S. (1996). “Encoding and Decoding in Television Discourse". In Hall, S. et al (eds.). Culture, Media, Language: working papers in Cultural Studies, 1972-1979 (pp. 128-138). London: Routledge.

Hall, S. (ed.) (2003). Representation. Cultural Representations and Signifying Practices. London: Sage.

Lopes, M.I.V. (2014). Memória e Identidade na Telenovela Brasileira. XXIII Encontro Anual da Compós. http:// compos.org.br/encontro2014/anais/ Docs/GT12_ESTUDOS_DE_TELEVISAO/ templatexxiiicompos_2278-1_2246.pdf

Lopes, M.I.V. (org.) (2009). Ficção Televisiva no Brasil: temas e perspetivas. Rio de Janeiro: Editorial Globo Universidade.

Lopes, M.I.V., Borelli, S. \& Resende, V. (2002). Vivendo com a telenovela: mediações, recepção, teleficcionalidade. São Paulo: Summus.

Machado, A. (2007). O sujeito na tela. Modos de enunciação no cinema e no ciberespaço. São Paulo: Paulus.

Mander, J. (1999). Quatro Argumentos para acabar com a televisão. Lisboa: Antígona.

Motter, M. L. (2000). “Telenovela e educação: um processo interativo". In Comunicação \& Educação, São Paulo, 17, pp. 54-60.

Nora, P. ([1993] 2001). Les Lieux de Mémoire. France: Gallimard.

Propp, V. (2003). Morfologia do Conto. Lisboa: Editora Vega.

Ramos, Jorge Leitão (2006). Dicionário do Cinema Português (1989-2003). Lisboa: Editorial Caminho.

Schiavo, M. (2002). "Merchandising social: as telenovelas e a construção de cidadania". Comunicação apresentada ao XXV Congresso Brasileiro de Ciências da Comunicação. Disponível em: http://www. intercom.org.br/papers/nacionais/2002/ congresso2002_anais/2002_np14schiavo.pdf. 
Singhal, A. et al. (eds). (2004).

Entertainment-Education and social

change. History research and practice.

London: Lawrence Erlbaum Associates.

Sobral, J. M. (2006). “Memória e Identidade

Nacional: considerações de caráter

geral e o caso português". Comunicação

apresentada ao Colóquio "Nação e Estado:

entre o local e o global". Disponível

em: http://www.ics.ul.pt/publicacoes/

workingpapers/wp2006/wp2006_4.pdf

Sousa, J. P. (2000). As notícias e os seus

efeitos: as "teorias" do jornalismo e dos

efeitos sociaisdos media jornalísticos.

Coimbra: Coimbra Minerva.

Sousa, V. (2018). Da 'Portugalidade' à

Lusofonia. Lisboa: Edições Humus.

Vogler, C. (2007). The writer's journey.

Mithic structure for writers. San Francisco:

Michael Wiese Production.

Relatório. Exposição Mundial de Lisboa de 1998. (1999). Lisboa: Parque Expo'98.

Creative Economy Report 2008. The

Challenge of Assessing the Creative

Economy: towards Informed Policy-making.

(2008). Nações Unidas. 